Document downloaded from:

http://hdl.handle.net/10251/32611

This paper must be cited as:

Abargues Llamas, M. R.; Robles Martínez, A.; Bouzas Blanco, A.; Seco Torrecillas, A. (2012). Micropollutants removal in an anaerobic membrane bioreactor and in an aerobic conventional treatment plant. Water Science and Technology. 65(12):2242-2250.

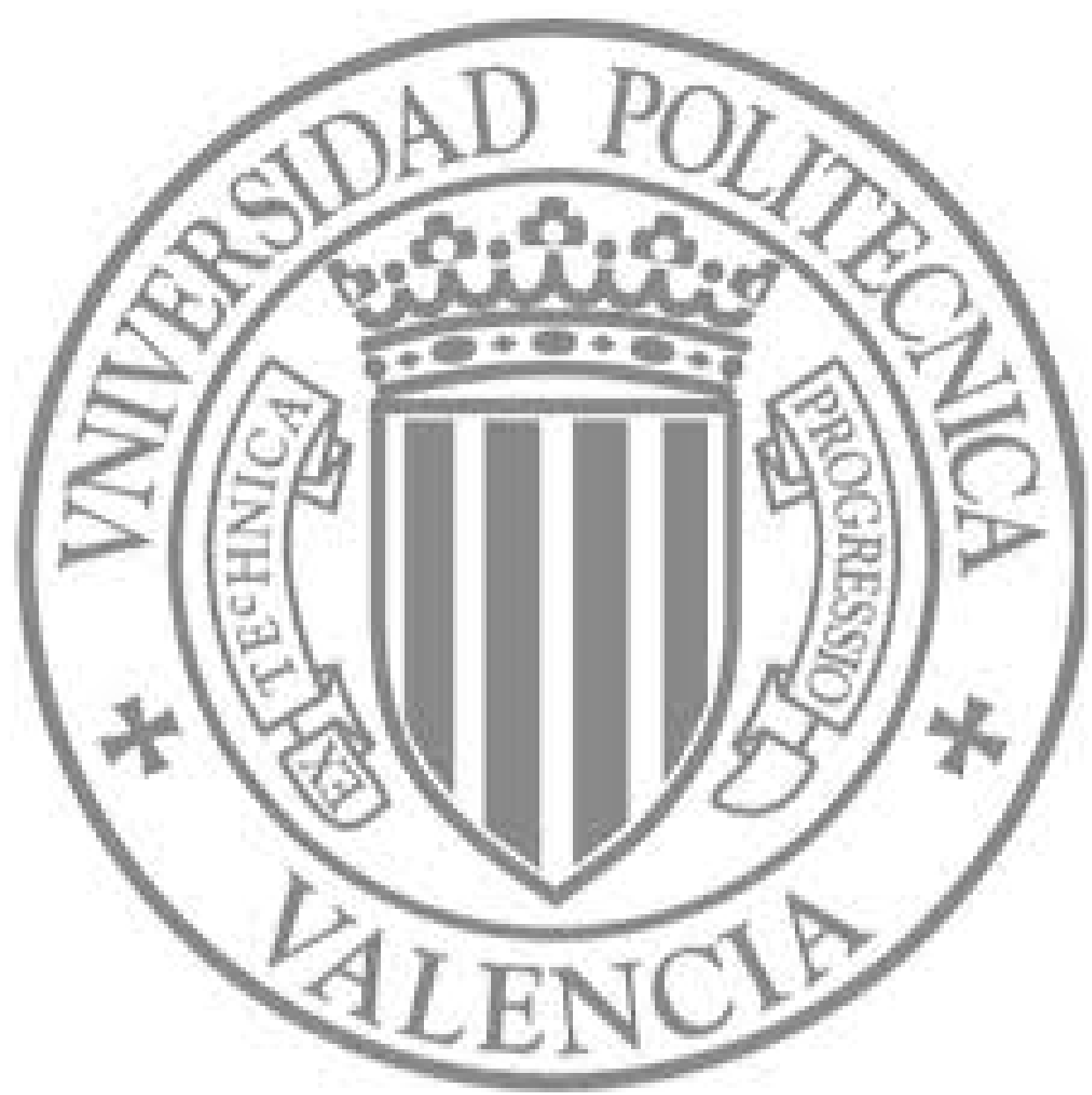

The final publication is available at

http://dx.doi.org/10.2166/wst.2012.145

Copyright IWA Publishing 


\title{
1 Micropollutants removal in an anaerobic membrane bioreactor and 2 in an aerobic conventional treatment plant
}

M.R. Abargues*, A. Robles**, A. Bouzas* and A. Seco*

* Dpto. Ingeniería Química, Universitat de València, Av. de la Universitat, s/n. 46100 Burjassot, Valencia, Spain (E-mail: miguel.abargues@uv.es; alberto.bouzas@uv.es; aurora.seco@uv.es)

** Instituto de Ingeniería del Agua y Medio Ambiente (IIAMA), Universidad Politécnica de Valencia, Camino de Vera, s/n 46022 Valencia, Spain (E-mail:ngerobma@upvnet.upv.es)

\begin{abstract}
The paper expresses an attempt to tackle the problem due to the presence of micropollutants on wastewater which may be able to disrupt the endocrine system of some organisms. These kinds of compounds are ubiquitously present in municipal wastewater treatment plant (WWTP) effluents. The aim of this paper is to compare the fate of the Alkylphenols-APs (4-(tert-octyl) phenol, t-nonylphenol and 4-p-nonylphenol and the hormones (estrone, 17ß-estradiol and 17a-ethinylestradiol) in a Submerged Anaerobic Membrane BioReactor (SAMBR) pilot plant and in a Conventional Activated Sludge wastewater treatment Plant (CTP). The obtained results are also compared with the results obtained in a previous study carried out in an aerobic MBR pilot plant. The results showed that the APs soluble concentrations in the SAMBR effluent were always significantly higher than the CTP ones. Moreover, the analyses of the suspended fraction revealed that the AP concentrations in the SAMBR reactor were usually higher than in the CTP reactor, indicating that under anaerobic conditions the APs were accumulated in the digested sludge. The aerobic conditions maintained both in the CTP system as in the aerobic MBR favoured the APs and hormones degradation, and gave rise to lower concentrations in the effluent and in the reactor of these systems. Furthermore, the results also indicated that the degradation of APs under aerobic conditions was enhanced working at high SRT and HRT values.
\end{abstract}

\section{Keywords}

Activated sludge plant, alkylphenols, endocrine disruptor, estrogenic hormones, membrane bioreactor.

\section{INTRODUCTION}

Nowadays society has changed its consumption habits, and high quantity of industrial products, drugs, and antibiotics are being produced. In developed countries, the increase of pharmaceuticals products prescription and consumption can be observed in the presence of these products on wastewater treatment plant streams, both in the sludge as in the effluent (Diaz et al., 2002; Kasprzyk-Hordern et al., 2008).

Among the great variety of non-natural substances that nowadays can be found in waters, the Alkylphenol Polyethoxylates (APEOs), its metabolites (Alkylphenols-APs) and certain hormones are being widely studied, due to their potential to act as endocrine disrupting compounds (EDCs) affecting the normal function of endocrine systems of some organisms. These micropollutants and other EDCs have been studied in surface waters (Bouzas et al., 2011; Martí et al., 2011; Ying et al., 2003)

APEOs are a group of compounds widely used as non-ionic surfactants with industrial, agricultural and domestic applications (Petrovic and Barceló 2010). APEOs can be degraded during the wastewater treatment process to APs (Giger et al., 1984, Lu et al., 2008): 4-p-nonylphenol (4-NP, CAS Number 104-40-5), 4-(1,1,3,3-tetramethylbutyl)phenol (OP; CAS Number 140-66-9) and technical nonylphenol (t-NP, CAS Number 84852-15-3). These APs are more toxic and lipophilic that APEOs and are considered as EDCs. Table 1 shows the chemical structure and the log $\mathrm{K}_{\mathrm{ow}}$, which provides a measure of bioaccumulation for each analyte. The estrogenic activity observed for APs appeared to be confined to para- or 4-substituted compounds (Jobling et al., 1993). The mentioned estrogenic activity becomes stronger with the increase in the number of the alkyl carbons. This activity is maximized with a nonylchain (Tabira et al., 1999).

Elimination of APEOs has been studied by several authors in Conventional Activated Sludge (CTP) or Membrane BioReactor (MBR) operational configurations. González et al. (2007) studied the removal of APEOs using a microfiltration aerobic MBR configuration working in parallel to a CTP working in aerobic conditions. The removal rates obtained in the MBR showed better results than the ones reported for the CTP. Similarly, Clara et al., (2005) concluded that removal of APEOs in aerobic conditions on ultrafiltration MBR system produces better results, but it is necessary an anaerobic step for a complete biodegradation of APEOs. Giger et al., (1984) studied the effect of APEOs on digested sludge concluding that alkylphenols mono- and di- ethoxylates are degraded to APs under anaerobic digestion and these metabolites are accumulated in the digested sludge. This was confirmed following 
the increase in the concentration of 4-NP and t-NP in anaerobic digested sludge, which indicates that anaerobic environments favour the accumulation of nonylphenols (Tan et al., 2008). As the degradation of APEOs into APs is promoted under anaerobic conditions, therefore the load of nonylphenols during anaerobic digestion is in most cases observed to increase on aqueous phase (Janex-Habibi et al., 2009).

Among the hormones, it is important to highlight estrone (E1, CAS Number 53-16-7) and 17ß-estradiol (E2, CAS Number 50-28-2), which are sexual female hormones, and 17a-ethynylestradiol (EE2, CAS Number 57-63-6), a synthetic estrogenic hormone, which are also considered as EDCs. 17ß-estradiol and estrone are natural hormones derived from excreta of humans and livestock. 17a-ethynylestradiol is the main component of the oral contraceptive pill. The biodegradation of E1, E2 and EE2 on wastewater treatment plant (WWTP) process seems to be very effective in both aerobic and anaerobic conditions (Joss et al., 2004, Zeng et al., 2009, Xu et al., 2012).

Table 1: Chemical Structure and log Kow of analysed compounds. Log Kow values for all compounds as predicted from ALOGPS 2.1 computer program provided by Virtual Computational Chemistry Laboratory (VCCLAB, 2005; Tetko et al., 2005)

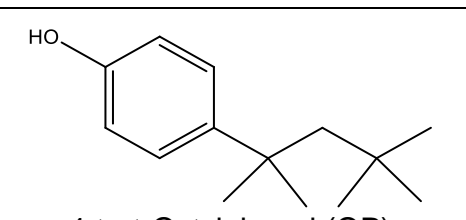

4-tert-Octylphenol (OP) Log Kow $=4.9$

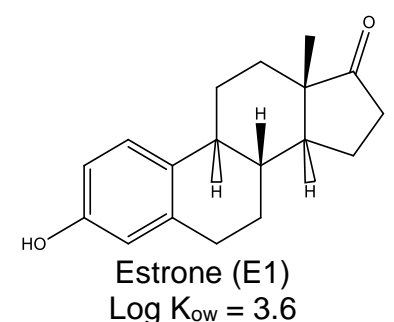

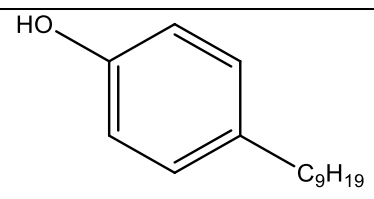

4-Nonylphenol (4-NP).

$\mathrm{C}_{9} \mathrm{H}_{19}$ is a lineal chain. Log $\mathrm{K}_{\mathrm{ow}}=5.8$

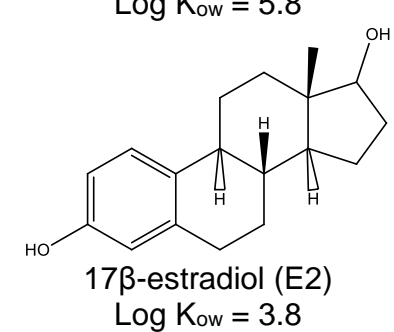

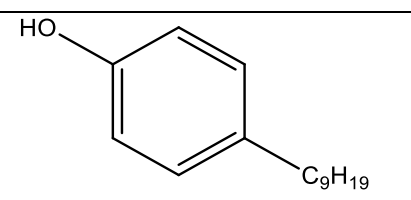

t-Nonylphenol (t-NP).

$\mathrm{C}_{9} \mathrm{H}_{19}$ is a branched chain Log $K_{\text {ow }}=5.7$

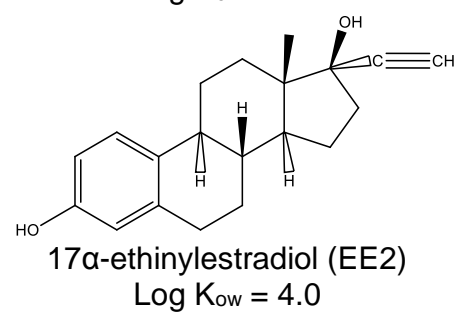

Directive 2000/60/EC, also known as Water Framework Directive (WFD), is probably the most significant international legislation introduced in the field of water from many years. WFD includes and protects different kinds of water in Europe (surface water, groundwater, transitional and coastal waters) with the aim of achieving and ensure a good quality for all of them. Moreover, Directive 2008/105/EC lays down environmental quality standards (EQS) for priority substances and certain other pollutants as provided for in WFD. These priority substances and other pollutants used to appear in waters at concentrations lower than $\mu \mathrm{g} / \mathrm{L}$. OP and 4-NP are included in the WFD as priority substances. Directive 2008/105/EC set the extent permitted of OP and 4-NP in inland and other surface waters, expressed as an annual average value (EQS-AA) or as maximum allowable concentration (EQS-MAC). The EQS-AA value for OP is $0.1 \mu \mathrm{g} / \mathrm{L}$ and $0.01 \mu \mathrm{g} / \mathrm{L}$ for inland and other surface waters respectively. The EQS-AA value for $4-\mathrm{NP}$ is $0.3 \mu \mathrm{g} / \mathrm{L}$ for inland and other surface waters and the EQS-MAC is $2.0 \mu \mathrm{g} / \mathrm{L}$. So, attention must be paid on the fate of these substances in order to fulfill the WFD requirements. E2 and EE2 are being considered to be included as priority substances in the WFD.

The APs and hormones, described above, are hydrophobic organic pollutants, and in aquatic environments tend to accumulate on the solid phases such as sediments, underwater fauna or WWTP sludge (Liu et al., 2004; Zhang et al., 2008). However, the magnitude of this accumulation is dependent on analytes and solid phase properties. Therefore, not only the aqueous phase but also the solid phases must be considered in order to study the fate of these micropollutants. The uses of APs and hormones make them very likely to be found in municipal and industrial wastewaters. Therefore, the fate of these substances and its metabolites in the WWTP must be considered in order to analyse their biological or physical removal.

The aim of this work is to compare the fate of the APs (OP, 4-NP and t-NP) and the hormones (E1, E2 and EE2) in a Submerged Anaerobic Membrane BioReactor (SAMBR) pilot plant and in a Conventional activated sludge wastewater Treatment Plant (CTP). The obtained results are also compared with the results obtained in a previous study carried out in an aerobic MBR pilot plant. 


\section{MATERIALS AND METHODS}

\section{Plants Description}

3 The three plants compared in this study (SAMBR, CTP and aerobic MBR) were located in Alboraya 4 (Valencia, Spain), and all of them received the same wastewater. The three plants were prepared for 5 organic matter removal without nitrogen removal.

The CTP, with a capacity of 140000 population equivalent, treated domestic wastewater combined with a small fraction of industrial wastewater. This CTP was operated at an average solid retention time (SRT) and hydraulic retention time (HRT) of $5 \mathrm{~d}$ and $4 \mathrm{~h}$ respectively. The CTP system mainly consists of a primary sedimentation, an aerobic reactor $\left(4192 \mathrm{~m}^{3}\right.$, average suspended solids between 2 and $3 \mathrm{~g} / \mathrm{L}$ ) and a secondary clarification.

The SAMBR consists of a rotary screening system $(0.5 \mathrm{~mm}$ screen size), an anaerobic bioreactor $\left(0.9 \mathrm{~m}^{3}\right.$ working volume, average suspended solids between 16 and $\left.22 \mathrm{~g} / \mathrm{L}\right)$ and two ultrafiltration membrane tanks $\left(0.6 \mathrm{~m}^{3}\right.$ working volume each one). Each membrane tank includes one industrial hollow-fibre ultrafiltration membrane module (PURON® Koch Membrane Systems (PUR-PSH31), $0.05 \mu \mathrm{m}$ pore size). The maximum value of transmembrane pressure reached was $0.08 \mathrm{bar}$. Each module consists of 9 hollow-fibre bundles of $1.8 \mathrm{~m}$ length that give a total of $30 \mathrm{~m}^{2}$ membrane surface. The pilot plant was operated at an average SRT of $80 \mathrm{~d}$ and at HRT of $8 \mathrm{~h}$, from October to January (period I), and $25 \mathrm{~h}$ from February to May (period II).

The third plant analysed in this paper consists of an aerobic immersed MBR pilot plant $\left(1 \mathrm{~m}^{3}\right.$ working volume, average suspended solids $15 \mathrm{~g} / \mathrm{L}$ ) with a submerged hollow-fibre ultrafiltration membrane module (Zenon, ZeeWeed® 500 module) with a total filtration surface of $46.5 \mathrm{~m}^{2}$. The membrane module is continuously aerated to minimize the fouling process. During the experimental period, the SRT was kept at $100 \mathrm{~d}$ and the HRT was $9 \mathrm{~h}$.

The SAMBR received degritted wastewater from the CTP while the aerobic MBR received settled wastewater from the primary settlers of the CTP. Table 2 shows the average wastewater characteristics of the influent to the three systems during the experimental period studied. This table highlights the significant sulphate concentration and the relatively low soluble Chemical Oxygen Demand (COD) concentration of the influent, as well as the strong variability of the influent load as can be deduced from the high values of standard deviation associated to each parameter.

Table 2. Average influent wastewater characteristics. "s.d." indicates the standard deviation.

\begin{tabular}{ccccc|ccc|ccc}
\hline & & \multicolumn{3}{c}{ SAMBR } & \multicolumn{3}{c|}{ CTP } & \multicolumn{3}{c}{ Aerobic MBR } \\
\hline Parameter & Units & Mean & \pm & s.d. & Mean & \pm & s.d. & Mean & \pm & s.d. \\
\hline TSS & $\mathrm{mgTSS} / \mathrm{L}$ & 330 & \pm & 90 & 115 & \pm & 30 & 120 & \pm & 40 \\
VSS & $\mathrm{mgVSS} / \mathrm{L}$ & 270 & \pm & 80 & 97 & \pm & 30 & 93 & \pm & 30 \\
Total COD & $\mathrm{mgCOD} / \mathrm{L}$ & 600 & \pm & 200 & 290 & \pm & 30 & 310 & \pm & 20 \\
Soluble COD & $\mathrm{mgCOD} / \mathrm{L}$ & 68 & \pm & 13 & 96 & \pm & 13 & 135 & \pm & 10 \\
VFA & $\mathrm{mgCOD} / \mathrm{L}$ & 9 & \pm & 5 & 6 & \pm & 3 & 12 & \pm & 2 \\
$\mathrm{SO}_{4}-\mathrm{S}$ & $\mathrm{mgS/L}$ & 102 & \pm & 9 & 112 & \pm & 7 & 110 & \pm & 10 \\
$\mathrm{NH}_{4}-\mathrm{N}$ & $\mathrm{mgN} / \mathrm{L}$ & 26 & \pm & 6 & 32 & \pm & 4 & 30 & \pm & 3 \\
$\mathrm{PO}_{4}-\mathrm{P}$ & $\mathrm{mgP} / \mathrm{L}$ & 3,5 & \pm & 1,5 & 5 & \pm & 2 & 4,2 & \pm & 1,3 \\
Alk & $\mathrm{mgCaCO} / \mathrm{L}$ & 310 & \pm & 80 & 350 & \pm & 30 & 300 & \pm & 40 \\
\hline
\end{tabular}

\section{Sampling}

The CTP and the SAMBR systems were studied from October 2010 to May 2011. In order to prevent systematic mistakes, collected samples were distributed randomly throughout the week during the studied period. The results of the aerobic MBR presented in this paper correspond to a previous work carried out from May to July 2009. A three-point sampling campaign was carried out in each plant in order to study the distribution and fate of APs and hormones.

In the SAMBR, three samples were collected: influent (after the rotary screener), anaerobic reactor and effluent (membrane permeate). In the CTP, the samples were collected after the primary sedimentation (influent), in the aerobic reactor and after the secondary clarification (effluent). Finally, 
for the aerobic MBR, the samples were taken after the CTP primary sedimentation (influent), in the MBR aerobic reactor and in the effluent (membrane permeate).

Influent and effluent samples were collected in glass bottles as $24 \mathrm{~h}$ composite samples while reactor ones were grab samples. Samples were centrifuged at $3500 \mathrm{rcf}$ for $10 \mathrm{~min}$ and filtered through $0.45 \mu \mathrm{m}$ nylon paper filters (Millipore, Bedford, MA) to remove suspended solids in order to separate the soluble fraction from the suspended fraction (excepting permeate samples). The soluble fraction was extracted by solid phase micro-extraction (SPME) and analysed by Gas Chromatography/Mass Spectrometry (GC/MS). The suspended fraction was dehydrated by freeze-dried, and later it was extracted with acetonitrile and analysed by GC/MS.

\section{Reagents and solutions}

All the reagents were of analytical grade. 4-p-nonylphenol (CAS Number 10440 5) and technical nonylphenol (CAS Number 84852-15-3) were obtained from Riedel-de Haën (Seelze, Germany). 4-(tert-octyl) phenol (CAS Number 140-66-9), estrone (CAS Number 53-16-7) and 17ß-estradiol (CAS Number 50-28-2) were purchased from Sigma-Aldrich (Steinheim, Germany). 17a-ethinylestradiol (CAS Number 57-63-6) was purchased from Fluka Biochemika (Steinheim, Germany). Methanol was purchased from Merck (Darmstadt, Germany). Pure water was obtained by means of a Milli-Q water purification system (Millipore, Bedford, MA, USA). Helium used as carrier gas was purchase from Carburos Metálicos (Barcelona, Spain). The stock solutions of standards were prepared in methanol up to a maximum concentration of $1000 \mathrm{mg} / \mathrm{L}$. The more dilute solutions were prepared from stock solutions directly in water up to a maximum concentration of $1 \mathrm{mg} / \mathrm{L}$. All solutions were kept at $4 \stackrel{\circ}{\circ} \mathrm{C}$ until use.

\section{Apparatus and chromatographic conditions}

The whole analyses were performed on a GC/MS system 6890 GC with 5973 MSD (Agilent, San José, USA). The capillary column was a fused-silica HP-5 MS (30.0 m, $250 \mu \mathrm{m}$ I.D., $0.25 \mu \mathrm{m}$ film thickness) (Agilent, San José, USA). Helium was used as carrier gas with a flow $1.0 \mathrm{~mL} / \mathrm{min}$. The transfer line was held at $280{ }^{\circ} \mathrm{C}$, and the ion source at $250 \stackrel{\circ}{\circ} \mathrm{C}$. The MS worked in selected-ion-monitoring mode and the electron impact energy was set to $69.9 \mathrm{eV}$. The gas chromatograph was operated in splitless mode and the injection port temperature was held isothermally at $280{ }^{\circ} \mathrm{C}$. The temperature program used was as follows: initial temperature of $50{ }^{\circ} \mathrm{C}, 30^{\circ} \mathrm{C} / \mathrm{min}$ to 140 , held for $1 \mathrm{~min}, 20{ }^{\circ} \mathrm{C} / \mathrm{min}$ to $280{ }^{\circ} \mathrm{C}$, held for $4 \mathrm{~min}, 30{ }^{\circ} \mathrm{C} / \mathrm{min}$ to 310 , held for $2 \mathrm{~min}$, for a total run time of $19 \mathrm{~min}$.

A SPME holder with replaceable extraction fibre was used for the extraction of the analytes. The fibre used in the study was coated with $85 \mu \mathrm{m}$ thickness polyacrylate. The SPME holder and the fibres were obtained from Supelco (Bellefonte, PA, USA). A magnetic stirrer and stir bars (VWR International Eurolab) were used for the extraction.

\section{Extraction procedures}

Different analytical methods were applied to determine the concentration of the analytes in the samples. The soluble fraction was analysed with direct immersion SPME with a polyacrylate fibre. 4 $\mathrm{mL}$ of sample were placed in a $4 \mathrm{~mL}$ clear vial screw top with a stir bar sorptive $(3 \mathrm{~mm}$ I.D., $6 \mathrm{~mm}$ width). The magnetic stirrer was set to 1500 r.p.m. for $30 \mathrm{~min}$. Afterwards, the SPME device was placed into the GC interface, set up at $280^{\circ} \mathrm{C}$, and the analytes were desorbed from the fibre under static mode during $3 \mathrm{~min}$. The dehydrated suspended fractions were analysed as described in detail in Campíns et al., 2008. Briefly, samples were extracted with a solid-phase extraction (SPE) procedure using acetonitrile as eluent. Then, the acetonitrile extract was mixed with an adequate volume of water and the same procedure used for the soluble fraction was followed. All experiments were performed in duplicate at room temperature.

\section{Analytical parameters}

The limits of detection (LOD) and quantification (LOQ) obtained for each micropollutant are presented in Table 3. The LOD was experimentally set as the concentration that produced a peak with a signal to noise ratio of 3 . The LOQ was defined as the concentration that produced a peak with a signal to noise ratio of 10 . 
Table 3: LODs and LOQs of the different micropollutants determined in the studied matrices

\begin{tabular}{ccccc}
\hline & \multicolumn{2}{c}{ Suspended Fraction $(\mu \mathrm{g} / \mathrm{kg})$} & \multicolumn{2}{c}{ Soluble Fraction $(\mu \mathrm{g} / \mathrm{L})$} \\
\hline Compound & LOD & LOQ & LOD & LOQ \\
OP & 0.7 & 2 & 0.006 & 0.02 \\
t-NP & 7 & 23 & 0.05 & 0.17 \\
4-NP & 4 & 13 & 0.01 & 0.03 \\
E1 & 45 & 150 & 0.25 & 0.8 \\
E2 & 40 & 133 & 0.15 & 0.5 \\
EE2 & 40 & 133 & 0.15 & 0.5 \\
\hline
\end{tabular}

\section{Results and Discussion}

The SAMBR and CTP systems were studied during the same period (October 2010 to May 2011), so the results of these plants are compared more extensively. The aerobic MBR study was performed in a previous period (May to July 2009), although influent wastewater to this aerobic MBR showed quite similar characteristics than the influent wastewater to the CTP (Table 2).

Table 4 and Table 5 shows statistical data for the analytes determined in the different sampling points for the soluble and the suspended fractions, respectively. Hormones (E1, E2 and EE2) were below LOD in the soluble fraction of SAMBR, CTP and aerobic MBR systems. The effluent of the SAMBR and aerobic MBR systems is a permeate, so no suspended fraction was obtained from the sample. As well, the concentration of suspended solids in the CTP effluent was very low and it was no possible to analyse its suspended fraction.

Table 4: Concentration levels (expressed as minimum, maximum and average) of micropollutants in each sampling point of SAMBR, CTP and aerobic MBR systems for the soluble fraction. The concentrations of hormones were lower than LOD. "s.d." expresses the standard deviation and "n.d." expresses "not detected".

\begin{tabular}{|c|c|c|c|c|c|c|c|c|c|c|c|c|}
\hline & \multicolumn{4}{|c|}{$O P(\mu g / L)$} & \multicolumn{4}{|c|}{$t-N P(\mu g / L)$} & \multicolumn{4}{|c|}{$4-N P(\mu g / L)$} \\
\hline & Max. & Min. & Average & s.d. & Max. & Min. & Average & s.d. & Max. & Min. & Average & s.d. \\
\hline$I_{\text {SAMBR }}$ & 0.987 & n.d. & 0.213 & 0.312 & 4.9 & n.d. & 2.3 & 1.1 & 3.2 & n.d. & 1.9 & 1.7 \\
\hline OSAMBR $_{\text {SAm }}$ & 1.240 & n.d. & 0.372 & 0.385 & 13.0 & 1.3 & 6.3 & 4.1 & 10.0 & n.d. & 4.6 & 4.8 \\
\hline $\mathrm{I}_{\text {СТP }}$ & 0.370 & n.d. & 0.096 & 0.124 & 6.7 & n.d. & 2.4 & 1.9 & 1.4 & n.d. & 1.9 & 2.3 \\
\hline$O_{\text {CTP }}$ & 0.084 & n.d. & 0.034 & 0.028 & 2.1 & n.d. & 1.0 & 0.6 & 0.8 & n.d. & 0.6 & 0.7 \\
\hline$I_{\text {aerobicMBR }}$ & 0,034 & 0,02 & 0,027 & 0,010 & 0,9 & 0,7 & 0,8 & 0,12 & 0,08 & 0,047 & 0,064 & 0,023 \\
\hline $\mathbf{O}_{\text {aerobicMBR }}$ & n.d. & n.d. & - & - & n.d. & n.d. & - & - & n.d. & n.d. & - & - \\
\hline
\end{tabular}

Regarding the soluble fraction, as can be observed in Table 4, the SAMBR effluent concentrations of OP, t-NP and 4-NP were always higher than in the influent, while the CTP effluent concentrations were lower than the influent ones. On the one hand, the anaerobic conditions in the SAMBR seem to favour APEOs degradation into APs that remain in the system under these anaerobic conditions. On the other hand, the CTP aerobic conditions seem to favour APs degradation, removing them from the system. The results obtained in the aerobic MBR also indicated that APs were degraded under aerobic conditions. These results are in accordance with the previous literature (Giger et al., 1984; Clara et al., 2005; Tan et al., 2008; Janex-Habibi et al., 2009). Moreover, comparing both aerobic systems (CTP and MBR), the operational parameters, SRT and HRT, seem to be important factors in APs removal from the soluble fraction since higher SRT and HRT values in the aerobic MBR led to higher removal rates. The APs removal was between 64 and $78 \%$ for the CTP and $100 \%$ for the aerobic MBR. Considering the soluble fraction results, the use of high SRT values has a lower influence on APs removal than the environmental conditions of the reactor. SAMBR and aerobic MBR systems worked at similar SRT and showed extremely different removal values (no removal in the SAMBR). Thus, the aerobic conditions are pointed out as the main factor in terms of APs reduction from the soluble fraction.

Among the APs studied, OP and t-NP showed the highest frequency of occurrence (92\% for OP and $93 \%$ for t-NP) in the soluble fraction. The results obtained in the soluble fraction for OP and t-NP are depicted in Figure 1 and Figure 2, respectively. The OP and t-NP influent concentrations to both 
systems were quite similar during the whole period. As stated before, the SAMBR effluent concentrations were always significantly higher than the CTP ones for both analytes.

Table 5: Concentration levels (expressed as minimum, maximum and average in dry weight) of micropollutants in each sampling point of SAMBR and CTP for the suspended fraction. The concentrations of E1 and E2 were lower than LOD. "s.d." represents the standard deviation.

\begin{tabular}{|c|c|c|c|c|c|c|c|c|}
\hline & \multicolumn{4}{|c|}{$O P(\mu g / k g)$} & \multicolumn{4}{|c|}{$t-N P(\mu g / k g)$} \\
\hline & Max. & Min. & Average & s.d. & Max. & Min. & Average & s.d. \\
\hline ISAMBR & 5570 & n.d. & 1180 & 1670 & 77700 & n.d. & 25900 & 27600 \\
\hline $\mathbf{R}_{\text {SAMBR }}$ & 11100 & n.d. & 1320 & 3180 & 60000 & n.d. & 22700 & 23700 \\
\hline Істр & 6200 & n.d. & 720 & 1760 & 183000 & n.d. & 29100 & 51300 \\
\hline \multirow[t]{3}{*}{$\mathbf{R}_{\text {CTP }}$} & 7100 & n.d. & 760 & 2020 & 90000 & n.d. & 14500 & 25600 \\
\hline & \multicolumn{4}{|c|}{ 4-NP ( $\mu g / k g)$} & \multicolumn{4}{|c|}{ EE2 $(\mu g / k g)$} \\
\hline & Max. & Min. & Average & s.d. & Max. & Min. & Average & s.d. \\
\hline ISAMBR & 108 & n.d. & 16 & 40 & 190 & n.d. & 26 & 62 \\
\hline RsAMBR & 82 & n.d. & 19 & 29 & 530 & n.d. & 63 & 160 \\
\hline$I_{\text {СтP }}$ & 100 & n.d. & 21 & 39 & 310 & n.d. & 26 & 89 \\
\hline $\mathbf{R}_{\mathbf{C T P}}$ & 180 & n.d. & 57 & 72 & 530 & n.d. & 79 & 186 \\
\hline
\end{tabular}

As can be seen in Table 5, the average suspended fraction concentrations in the SAMBR and CTP influent showed similar values. This result indicated that the different pretreatments suffered by the wastewater (rotary screening and primary settling, respectively) did not significantly affect the concentration in the suspended fraction. t-NP and OP showed the highest concentrations in the suspended fractions both in the influent as in the reactor. In general, the corresponding concentrations for OP and t-NP in the reactor suspended fraction were higher in the SAMBR than in the CTP. This could be explained due to under anaerobic conditions and high SRT, the APs were retained in the suspended fraction, while under aerobic conditions APs were degraded. In the aerobic MBR, only t-NP was found in the suspended fraction of the reactor, showing a maximum concentration of $8000 \mu \mathrm{g} / \mathrm{kg}$. Comparing both aerobic systems (CTP and MBR), the suspended fraction concentrations found in the aerobic MBR were quite lower than the concentrations found in the CTP. This could be explained attending to the SRT value in each system. The high SRT value in the aerobic MBR could have improved the APs degradation in the suspended fraction since APs kept retained under aerobic conditions during a longer period. Despite no hormones were found in the soluble fraction, EE2 was found in the influent and in the reactor suspended fractions of CTP and SAMBR systems. No hormones were detected in the aerobic MBR, indicating that this configuration also favoured hormones degradation. Nevertheless, more data on aerobic MBR through a longer period should be necessary to confirm that.

Among the APs studied, OP and t-NP showed the highest frequency of occurrence (83 and $100 \%$ for $\mathrm{OP}$ and $\mathrm{t}-\mathrm{NP}$ respectively) in the suspended fraction. Figure 3 and Figure 4 showed the results obtained for these two micropollutants.

In the SAMBR, it can observed that OP and t-NP concentrations during period I (October to January) were lower than in period II (February to May), except for October $6^{\text {th }}$ 2010. This behaviour can be attributed to the HRT used in the SAMBR, $8 \mathrm{~h}$ (period I) and $25 \mathrm{~h}$ (period II). The longer HRT under anaerobic conditions allowed a grater APs release from APEOs degradation and subsequently a greater retention in the sludge due to their high potential of bioaccumulation (log $K_{\text {ow }}$ between 4.9 and 5.8). 


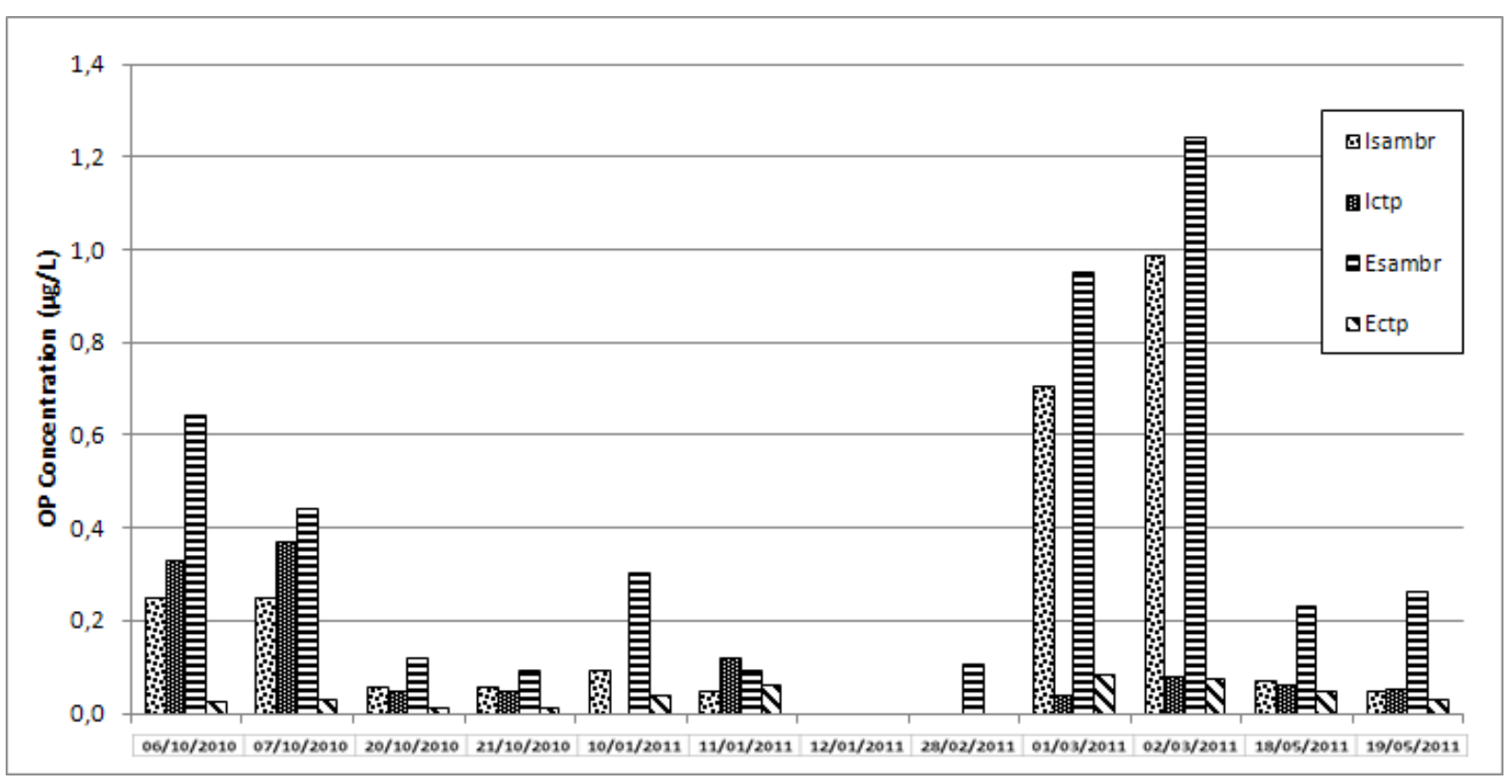

Figure 1: Results obtained for analysis of OP in the soluble fraction samples. ISAMBR is the influent to SAMBR, ICTP is the influent to CTP, $E_{\text {SAMBR }}$ is the effluent of SAMBR and $E_{\text {CTP }}$ is the effluent of CTP

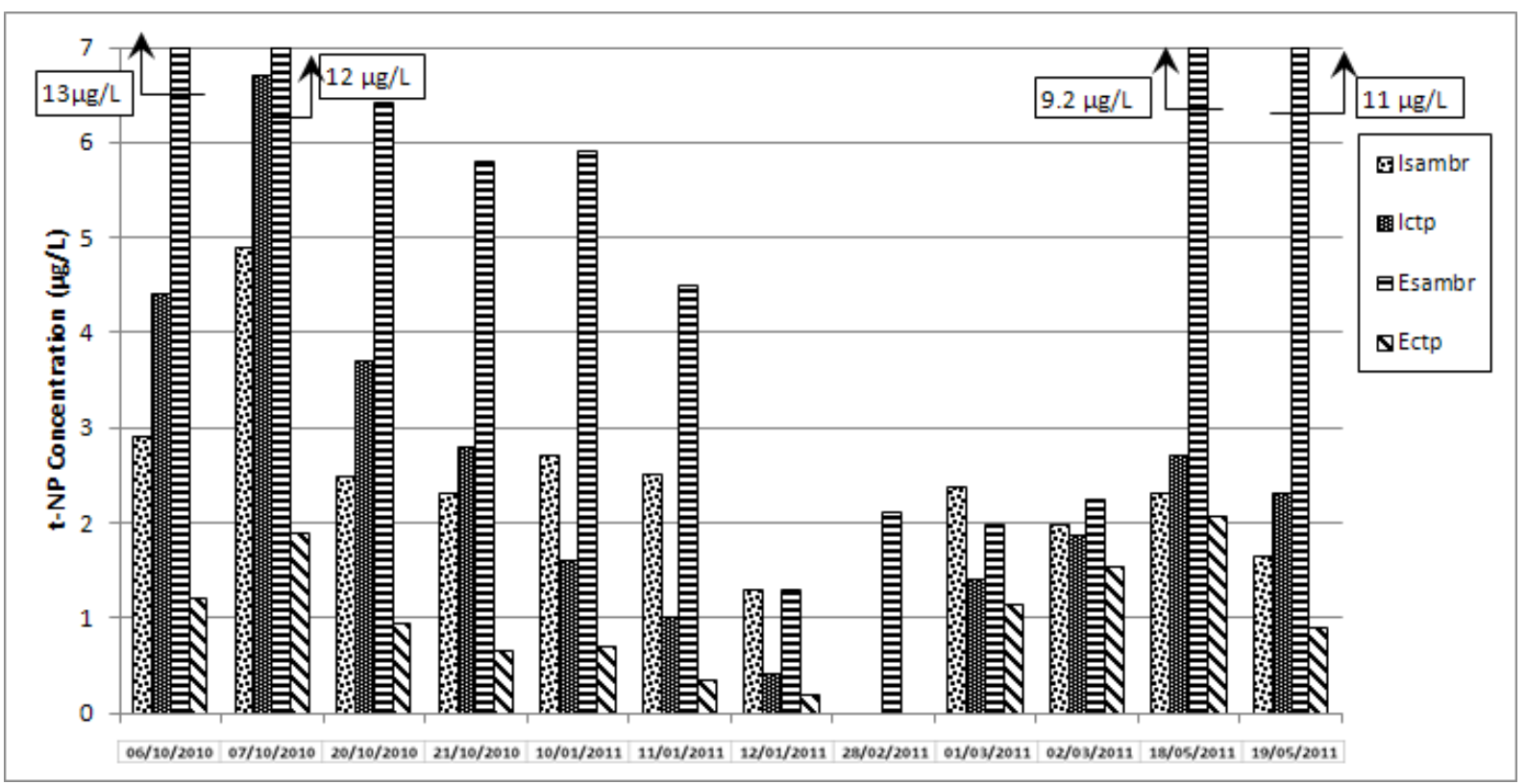

Figure 2: Results obtained for analysis of t-NP in the soluble fraction samples. IsAMBR is the influent to SAMBR, ICTP is the influent to CTP, ESAMBR is the effluent of SAMBR and $E_{\text {CTP }}$ is the effluent of CTP. 


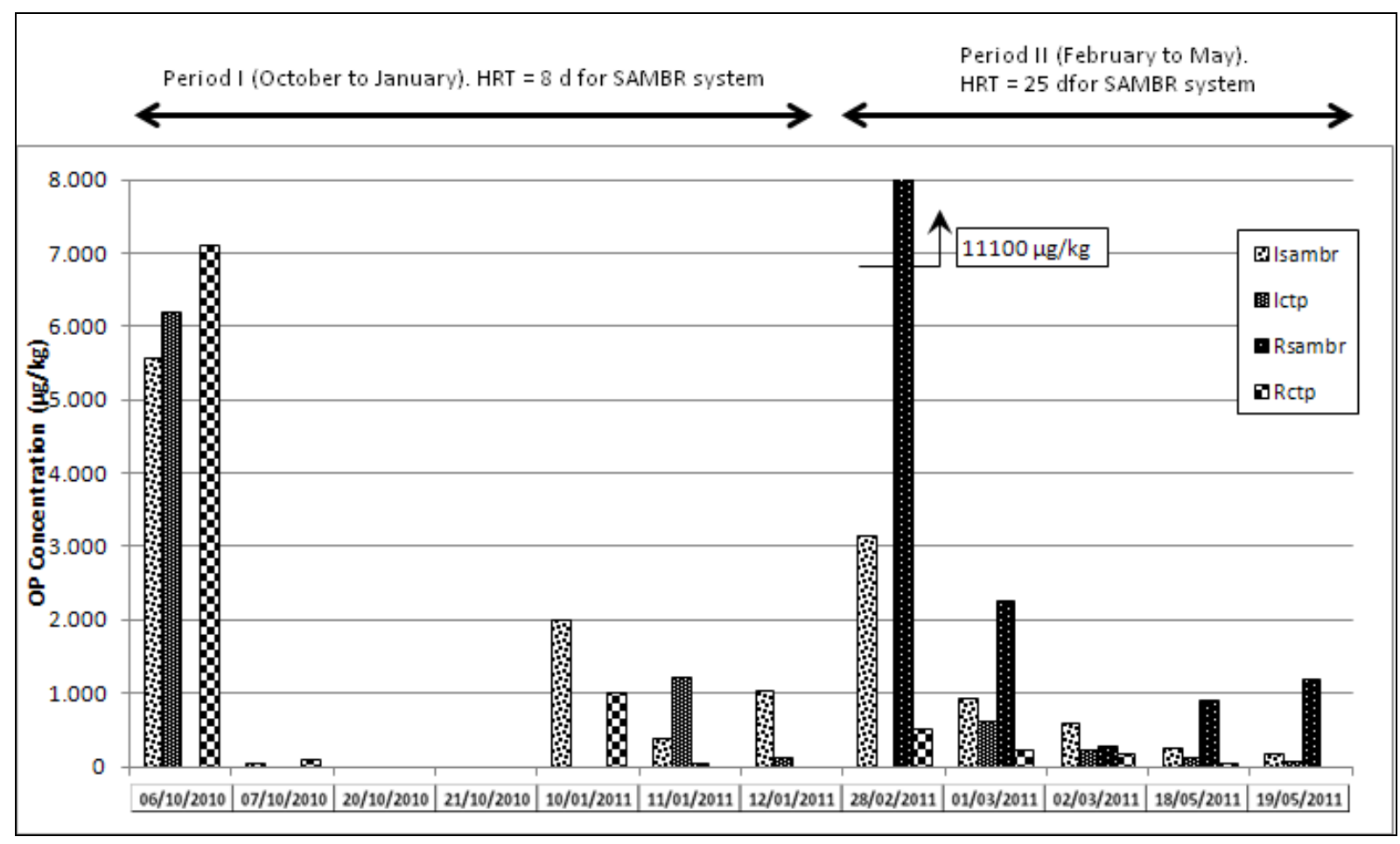

Figure 3: Results obtained for analysis of OP in the suspended fraction samples (dry weight). ISAMBR is the influent to SAMBR, ICTP is the influent to CTP, $R_{C T P}$ is a sample of CTP reactor and $R_{S A M B R}$ is a sample of SAMBR reactor.

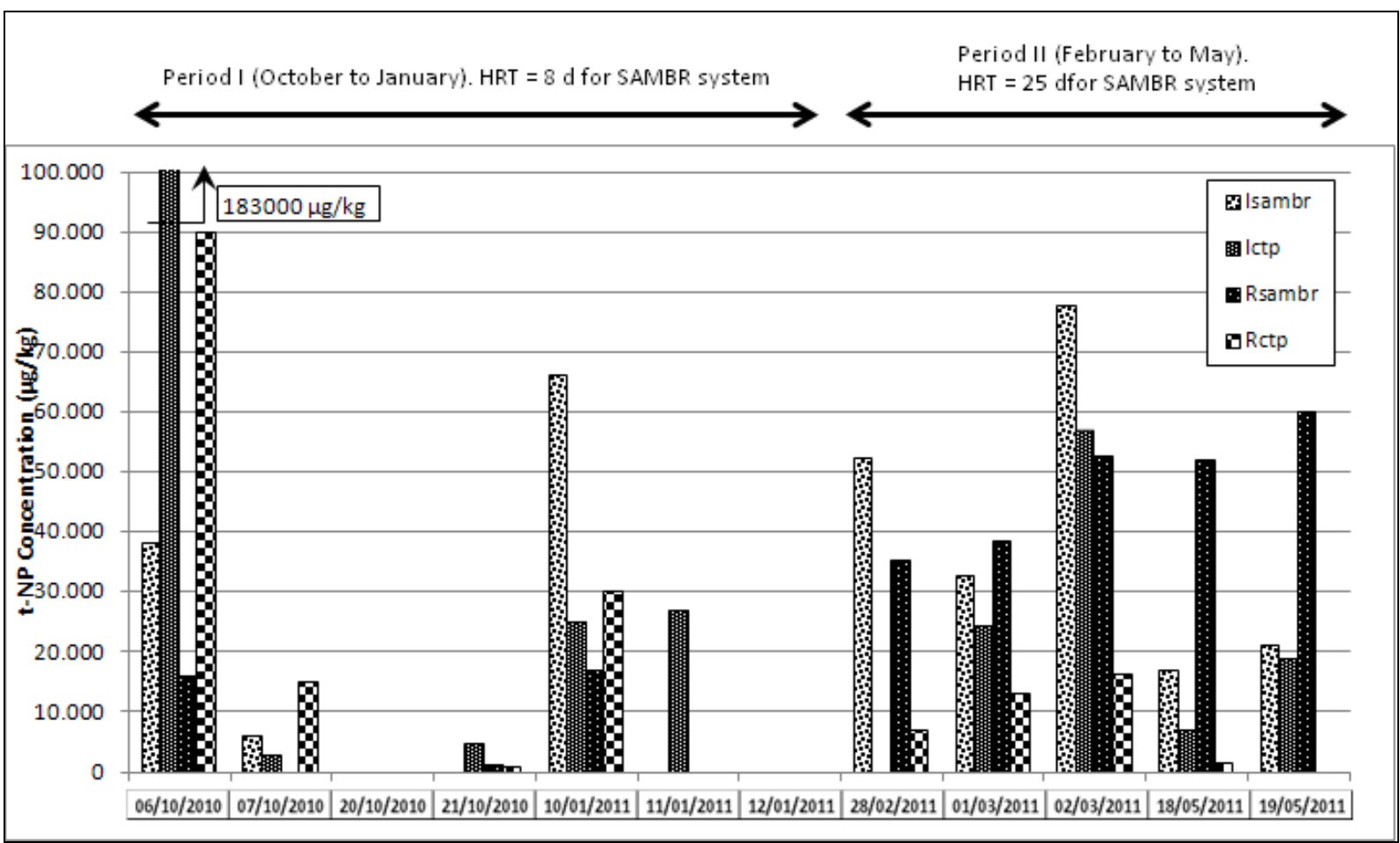

Figure 4: Results obtained for analysis of t-NP in the suspended fraction samples (dry weight). ISAMBR is the influent to SAMBR, IстP is the influent to CTP, RсTP is a sample of CTP reactor and RsAmBR is a sample of SAMBR reactor. 


\section{CONCLUSIONS}

2 The fate of the APs (OP, 4-NP and t-NP) and the hormones (E1, E2 and EE2) in a Submerged 3 Anaerobic Membrane BioReactor (SAMBR) pilot plant, a Conventional activated sludge wastewater

\section{References}

\section{Acknowledgement}

This research was financially supported by The Government of the Region of Valencia (Generalitat Valenciana), within the research project "Application of Water Framework Directive 2000/60/EC on endocrine disruptors and priority substances in coastal areas in the Comunidad Valenciana" and by the Spanish Research Foundation (MICINN, project CTM2008-060809-C02-01/TECNO), within the research project "Feasibility of the SAMBR technology to treat urban wastewater, and the technical and economic feasibility to industrial implementation".

Bouzas A. Aguado D., Martí N. Pastor J.M., Herráez·R., Campins P., Seco A. (2011). Alkylphenols and polycyclic aromatic hydrocarbons in eastern Mediterranean Spanish coastal marine bivalves. Environ Monit Assess (2011) 176:169-181.

Campíns-Falcó P., Verdú-Andrés J., Sevillano-Cabeza A., Molins-Legua C., Herráez-Hernández R. (2008) New micromethod combining miniaturized matrix solid-phase dispersion and in-tube in-valve solid-phase microextraction for estimating polycyclic aromatic hydrocarbons in bivalves. Journal of Chromatography $A, 1211$ (2008) 13-21.

Clara M., Strenn B., Gans O., Martinez E., Kreuzinger N., Kroiss H. (2005) Removal of selected pharmaceuticals, fragrances and endocrine disrupting compounds in a membrane bioreactor and conventional wastewater treatment plants. Water Research 39 (2005) 4797-4807.

Diaz A., Ventura F., Galceran M.T. (2002). Development of a solid-phase microextraction method for the determination of short-ethoxy-chain nonylphenols and their brominated analogs in raw and treated water. Journal of Chromatography A, 963 (2002) 159-167.

EC (2000). Directive 2000/60/EC of the European Parliament and of the Council of 23 October 2000 establishing a framework for community action in the field of water policy. Official Journal of the European Communities, L, 327,1 .

EC (2008). Directive 2008/105/EC of the European Parliament and of the Council of 16 December 2008 on environmental quality standards in the field of water policy, amending and subsequently repealing Council Directives 82/176/EEC, 83/513/EEC, 84/156/EEC, 84/491/EEC, 86/280/EEC and amending Directive 2000/60/EC of the European Parliament and of the Council. Official Journal of the European Communities, L, 348,84. 
Giger W., Brunner P., Schaffner C. (1984) 4-nonylphenol in Sewage Sludge: Accumulation of Toxic Metabolites from Nonionic Surfactants. Science, New Series, Vol. 225, No. 4662. (Aug. 10, 1984), pp. 623-625.

González S., Petrovic M., Barceló D. (2007) Removal of a broad range of surfactants from municipal wastewater-Comparison between membrane bioreactor and conventional activated sludge treatment. Chemosphere 67 (2007) 335-343.

Janex-Habibi M.L., Huyard A., Esperanza M., Bruchet A. (2009) Reduction of endocrine disruptor emissions in the environment: The benefit of wastewater treatment. Water Research 43 (2009) 1565-1576.

Joss A., Andersen H., Ternes T., Richle P.R., Siegrist H., (2004). Removal of estrogens in municipal wastewater treatment under aerobic and anaerobic conditions: consequences for plant optimization. Environmental Science \& Technology 38, 3047-3055.

Jobling S., Sumpter J. (1993). Detergent components in sewage effluent are weakly oestrogenic to fish: An in vitro study using rainbow trout (Oncorhynchus mykiss) hepatocytes. Aquatic Toxicology Vol. 27 1993, Issues 3-4, 361-372.

Kasprzyk-Hordern B., Dinsdale R.M., Guwy A.J. (2008). The occurrence of pharmaceuticals, personal care products, endocrine disruptors and illicit drugs in surface water in South Wales, UK. Water Research 42 (2008) 3498- 3518.

Martí N., Aguado D., Segovia-Martínez L., Bouzas A., Seco A. (2011). Occurrence of priority pollutants in WWTP effluents and Mediterranean coastal waters of Spain. Marine Pollution Bulletin 62 (2011) 615-625.

Liu R., Zhou J.L., Wilding A. (2004). Microwave-assisted extraction followed by gas chromatography-mass spectrometry for the determination of endocrine disrupting chemicals in river sediments. Journal of Chromatography A, 1038 (2004) 19-26.

Lu J., Jin Q., He Y., Wu J., Zhang W., Zhao J. (2008) Biodegradation of nonylphenol polyethoxylates by denitrifying activated sludge. Water Research 42 (2008) 1075- 1082.

Petrovic M., Barcelo D. (2010) Fate and Occurrence of Surfactants-Derived Alkylphenolic Compounds in Conventional and Membrane Bioreactor (MBR) Wastewater Treatment Plants. Environmental Pollution, 2010, Volume 16, Part III, 375-385.

Tabira Y., Nakai M., Asai D., Yakabe Y., Tahara Y., Shinmyozu T., Noguchi M., Takatsuki M., Shimohigashi Y. (1999) Structural requirements of para-alkylphenols to bind to estrogen receptor. Eur. J. Biochem. Volume 262, 240-245 (1999).

Tan B.L.L., Hawker D.W., Müller J.F., Tremblay L.A., Chapman H.F. (2008) Stir bar sorptive extraction and trace analysis of selected endocrine disruptors in water, biosolids and sludge samples by thermal desorption with gas chromatography-mass spectrometry. Water Research 42 (2008) 404-412.

Tetko I. V., Gasteiger J., Todeschini R., Mauri A., Livingstone D., Ertl P., Palyulin V. A., Radchenko E. V., Zefirov N.S., Makarenko A.S., Tanchuk V.Yu., Prokopenko V.V. (2005). Virtual computational chemistry laboratory design and description. Journal of Computer-Aided Molecular Design (2005) 19: 453-463.

VCCLAB (Virtual Computational Chemistry Laboratory), 2005. ALOGPS 2.1. Website located at: $<$ http://www.vcclab.org>.

Xu N., Xu Y.F., Xu S., Li J., Tao H.C. (2012) Removal of estrogens in municipal wastewater treatment plants: A Chinese perspective. Environmental Pollution (2012), doi:10.1016/j.envpol.2011.12.025.

Ying G.G., Kookana R.S. (2003). Degradation of Five Selected Endocrine-Disrupting Chemicals in Seawater and Marine Sediment. Environ. Sci. Technol. 2003, 37, 1256-1260.

Zeng Q, Li Y, Gu G, (2009). Nitrate-dependent degradation of $17 \alpha$-ethinylestradiol by acclimated activated sludge under anaerobic conditions. Journal of Chemical Technology \& Biotechnology 84, 1841-1847.

Zhang Y., Zhou J.L. (2008). Occurrence and removal of endocrine disrupting chemicals in wastewater. Chemosphere 73 (2008) 848-853. 